\title{
The Factor-of-Risk Biomechanical Approach Predicts Hip Fracture In Men and Women: The Framingham Study
}

\author{
Alyssa B. Dufour, MA ${ }^{1,2}$, Benjamin Roberts ${ }^{4}$, Kerry E. Broe, MPH $^{2}$, Douglas P. Kiel, MD, \\ $\mathbf{M P H}{ }^{2,3,5}$, Mary L. Bouxsein, $\mathbf{P h D}^{3,4}$, and Marian T. Hannan, $\mathbf{S c D}, \mathbf{M P H}{ }^{2,3,5}$ \\ ${ }^{1}$ Department of Biostatistics, Boston University School of Public Health, Boston, MA, USA \\ 2Institute for Aging Research, Hebrew SeniorLife, Boston, MA, USA \\ ${ }^{3}$ Harvard Medical School, Boston, MA, USA \\ ${ }^{4}$ Orthopedic Biomechanics Laboratory, Beth Israel Deaconess Medical Center, Boston, MA, USA \\ ${ }^{5}$ Division of Gerontology, Department of Medicine, Beth Israel Deaconess Medical Center, \\ Boston, MA, USA
}

\begin{abstract}
Purpose-Alternative methods of predicting hip fracture are needed since $50 \%$ of adults who fracture do not have osteoporosis by BMD measurements. One method, factor-of-risk $(\varphi)$, computes the ratio of force on the hip in a fall, to femoral strength. We examined the relation between $\varphi$ and hip fracture in 1,100 subjects from the Framingham Study with measured hip BMD, along with weight, height and age, collected in 1988-89.
\end{abstract}

\begin{abstract}
Methods-We estimated both peak and attenuated force applied to the hip in a sideways fall from standing height, where attenuated force incorporated cushioning effects of trochanteric soft tissue. Femoral strength was estimated from femoral neck BMD, using cadaveric femoral strength data. Sex-specific, age-adjusted survival models were used to calculate hazard ratios (HR) and 95\% confidence intervals for the relation between $\varphi_{\text {peak }}, \varphi_{\text {attenuated }}$ and their components, with hip fracture.
\end{abstract}

Results-In 425 men and 675 women (mean age 76 yrs), 136 hip fractures occurred over median follow-up of 11.3 yrs. $\varphi$ was associated with increased age-adjusted risk for hip fracture. One standard deviation increase in $\varphi_{\text {peak }}$ and $\varphi_{\text {attenuated }}$ was associated with HR of 1.88 and 1.78 in men and 1.23 and 1.41 in women, respectively. Examining components of $\varphi$, in women, we found fall force and soft tissue thickness were predictive of hip fracture independent of femoral strength, (was estimated from BMD).

Conclusions-Thus, both $\varphi_{\text {peak }}$ and $\varphi_{\text {attenuated }}$ predict hip fracture in men and women. These findings suggest additional studies of $\varphi$ predicting hip fracture using direct measurements of trochanteric soft tissue.

Corresponding author: Alyssa B. Dufour, MA Institute for Aging Research Hebrew SeniorLife 1200 Centre St. Boston, MA 02131 Office (617) 971-5363 Fax (617) 971-5339 alyssadufour@hrca.harvard.edu.

alyssadufour@hrca.harvard.edu

bjrobert@bidmc.harvard.edu

broe@hrca.harvard.edu

kiel@hrca.harvard.edu

mbouxsei@bidmc.harvard.edu

hannan@hrca.harvard.edu

Conflict of Interest: Dr. Douglas P. Kiel is involved in research grants from Novartis, Merck, Amgen, Pfizer, and Hologic, and consulting for GlaxoSmithKline, Merck, Novartis, Amgen, Eli Lilly, Procter \& Gamble, Wyeth, and Sanofi Aventis. All other authors have no relevant conflicts of interest. 


\section{Keywords}

Hip fracture; Factor-of-Risk; bone strength; cohort study; fracture prediction; elderly

\section{Introduction}

Hip fractures are the most costly and debilitating of all osteoporotic fractures and their incidence is predicted to double or triple in the coming decades, due to the growing numbers of elderly individuals ${ }^{1-2}$. Many risk factors for hip fracture have been identified from epidemiologic studies, including older age, sex, use of alcohol, tobacco or glucocorticoids, family history of fracture, low bone mineral density (BMD), previous history of fracture, and low body weight or low body mass index (BMI) ${ }^{3-4}$. Currently, the most common tool for diagnosis of osteoporosis and prediction of fracture risk is BMD by dual-energy X-ray absorptiometry (DXA). Yet, up to half of individuals suffering a hip fracture do not have osteoporosis by BMD testing 5 . There is a compelling need to improve the prediction of hip fracture risk and enhance identification of those at greatest risk, in order to intervene with therapies and/or non-pharmacologic strategies proven to reduce hip fracture incidence. This need led to the development of the FRAX risk assessment tool from the World Health Organization that uses multiple risk factors to assess absolute fracture risk based on multiple cohort study data ${ }^{4}$. The FRAX assessment tool does not specifically take into account falls and fall-related risk factors, even though falls are critically important for hip fracture. ${ }^{6-7}$ Incorporating fall characteristics into a hip fracture prediction tool could potentially improve our ability to assess fracture risk.

Since a hip fracture is a structural failure, wherein the loads applied to the femur exceed its strength, a biomechanical approach to hip fracture risk evaluation may improve fracture risk assessment ${ }^{8}$. The factor-of-risk, defined as the ratio of applied forces to bone strength, is one biomechanical approach to fracture risk assessment. Theoretically when the factor-of-risk exceeds one, a fracture would be predicted to occur ${ }^{9-10}$. Age- and sex-specific differences in the factor-of-risk generally reflect the observed incidence of wrist, hip and vertebral fractures more closely than do differences in $\mathrm{BMD}^{11-13}$. In applying this biomechanical concept to hip fractures, one must estimate the forces applied to the hip during the activity that causes a hip fracture, which is most often a sideways fall from standing height ${ }^{14-16}$, and the strength of the proximal femur in a sideways fall condition. Forces applied to the hip during a fall depend on the fall characteristics, impact surface, self-protective responses, and thickness of soft tissues overlying the hip.

Regarding the utility of the factor of risk to predict hip fracture, a small case-control study of postmenopausal women, with small numbers of hip fractures, showed that an increased factor-of-risk was associated with greater risk of hip fracture ${ }^{3}$. However, after further adjustment for femoral BMD, the factor-of-risk was no longer significantly associated with hip fracture. In men over the age of 65 , an increased factor-of-risk was also associated with a greater risk of hip fracture ${ }^{17}$, but after adjustment for BMD, the factor-of-risk was no longer associated with hip fracture. A second study was performed in older men (40 hip fractures), using a load-to-strength ratio that utilized QCT-based finite element analysis to estimate femoral strength but did not account for trochanteric soft tissue thickness in estimating the forces applied to the hip. A 4-fold increased risk of hip fracture was observed per standard deviation increase in the load-to-strength ratio ${ }^{18}$. A limitation of this prior work on the factor-of-risk and hip fracture is that there has been no prospective study with men and women studied from the same population. 
To better understand the factors associated with hip fracture in both women and men, we tested whether the factor-of-risk ${ }^{8-9}$ predicts hip fracture in men and women, in members of the population-based Framingham study. Additionally, we examined the association between the components of factor-of-risk (fall force, femoral strength and estimated trochanteric soft tissue thickness) and risk of hip fracture to determine whether the components of the factor-of-risk contribute independently to the prediction of hip fractures. We hypothesized that the factor-of-risk would be associated with risk of hip fracture and its components (fall force, femoral strength and estimated trochanteric soft tissue thickness) would also be associated with hip fracture .

\section{Materials and Methods}

\section{Study Sample}

The study sample was derived from the Framingham Study, a large, longitudinal populationbased study that began in 1948 with the enrollment of 5,209 men and women who were 28 to 62 years of age. A two-thirds sample from the town of Framingham, MA was recruited in order to study risk factors for heart disease ${ }^{19}$. The cohort has been followed biennially since that time. The Framingham Study cohort is representative of the general population with respect to numerous characteristics including the frequency distribution of age and sex, cardiovascular morbidity and mortality, and incidence rates of first hip fracture ${ }^{20-23}$. Followup information on mortality and fracture is complete for over 95\% of the Framingham Study participants. 1,100 cohort members with baseline hip scans acquired between 1988 and 1989 were included in this analysis.

At this baseline exam in 1988-89, dual-photon absorptiometry (DPA) scans of the hip were obtained using a Lunar DP3 (Lunar, Madison, WI) and used to derive BMD of the femoral neck. Weight in pounds was measured at baseline using a standardized balance beam scale and recorded to the nearest $1 / 2$ pound. Height (without shoes) was measured at baseline in inches using a calibrated stadiometer and recorded to the nearest $1 / 4$ inch. BMI was calculated from these measures in $\mathrm{kg} / \mathrm{m}^{2}$.

\section{Fracture Ascertainment}

Hip fractures have been continuously ascertained in all members of the cohorts and validated by the Framingham Osteoporosis Study through December 31, 2005. Hip fracture ascertainment is done through review of all participant contacts or visits to the Framingham Clinic, and review of all hospitalizations (admission notes, emergency room notes, operative reports, x-ray reports and discharge summaries), physician contacts, and deaths. Fracture adjudication is an ongoing process using all of these data sources to document the details surrounding the fracture, the circumstances of the fracture, degree of trauma (fall from less than or greater than standing height, motor vehicle accident, etc.), location of the fracture (intertrochanteric, femoral neck, other) and treatment for the fracture. Based on previous record review, the Registry has $>98 \%$ complete follow-up for hip fractures, and the rate of hip fractures in this cohort is in agreement with published values ${ }^{23}$.

We examined incident hip fractures that occurred after the baseline measure of BMD through December 31, 2005. Pathological fractures and fractures due to severe trauma (motor vehicle accident, or assault) were excluded. Fracture cases were defined as participants who suffered at least one validated, adjudicated hip fracture occurring after their baseline BMD scan. History of fracture was defined as a hip fracture occurring prior to the baseline BMD scan. Subjects with a history of fracture ( 2 men and 25 women) were not excluded from the analysis. 


\section{Factor-of-Risk $(\varphi)$}

We calculated $\varphi$ as the ratio of applied force to femoral strength. The numerator was calculated two ways: either using estimated peak force or attenuated force applied to the hip in a sideways fall from standing height. The components of the Factor-of-Risk were computed as follows:

$$
\text { Factor }- \text { of }- \text { Risk }=\frac{\text { force }}{\text { femoralstrength }}
$$

The peak force applied to the hip was estimated from each subject's height $(\mathrm{m})$ and weight $(\mathrm{kg})$, using a published equation derived from biomechanical modeling of a sideways fall from standing height ${ }^{24-25}$.

$$
\text { Peak Force }(\mathrm{N})=\text { sqrt }(2 g h m k) \text {, }
$$

where $g$ is the gravitational constant $\left(9.81 \mathrm{~m} / \mathrm{s}^{2}\right), h$ is the height of an individual's center of gravity for a fall from standing height, taken as $0.51 *$ height (in meters), $m$ is the effective mass (in $\mathrm{kg}$ ), and $k$ is the stiffness constant ( $\mathrm{N} / \mathrm{m} ; k=71,060$ in women, $k=90,440$ in men) ${ }^{25}$. The stiffness constant reflects the response of the body to an impact force directed at the greater trochanter, and was derived from experiments in human volunteers ${ }^{25}$. We also computed an "attenuated force" using the observation by Robinovitch et al ${ }^{26}$ that the peak force applied to the hip is reduced by $71 \mathrm{~N}$ per $\mathrm{mm}$ increase of trochanteric soft tissue. The ideal method for determining trochanteric soft tissue thickness would be to measure the distance between the most lateral aspect of the greater trochanter and the lateral aspect of the skin-air boundary on a whole body DXA scan or 3D CT image of the femoral region. As we were not able to collect these direct measurements for this study, we estimated each individual's trochanteric soft tissue thickness from previously published, sex-specific regressions of trochanteric soft tissue thickness on $\mathrm{BMI}^{3,17}$. For men, trochanteric soft tissue thickness (mm) is equal to $3.4795 *\left(B M I\left(\mathrm{~m} / \mathrm{kg}^{2}\right)\right)-38.015$. For women, trochanteric soft tissue thickness $(\mathrm{mm})$ is equal to $2.3415^{*}\left(\mathrm{BMI}\left(\mathrm{m} / \mathrm{kg}^{2}\right)\right)$ - 33.444. Femoral strength in a sideways fall configuration was derived from the linear regression between femoral neck BMD and femoral failure load determined from previous mechanical testing in cadaveric specimens ${ }^{27}$. Specifically, the regressions between femoral neck BMD and femoral strength in a sideways fall configuration were determined from in vitro experiments using 73 human femora from 48 women and 28 men, aged $55-98 \mathrm{yrs}_{\text {of age }}{ }^{27}$. The derived regression between BMD and femoral strength is the same for men and women, and does not differ by age: Femoral strength $=8207 *\left(\right.$ femoral neck BMD $\left.\left(\mathrm{g} / \mathrm{cm}^{2}\right)\right)-568.62$.

\section{Data analysis}

Descriptive statistics were generated using means and standard deviations for continuous measures and frequencies and percentages for categorical measures. Separate baseline descriptive statistics were generated for men and women, and for participants who either sustained or did not sustain a hip fracture during follow-up.

Crude and age-adjusted Cox Proportional Hazards regressions were used to calculate hazard ratios (HR) and 95\% confidence intervals (CI) for the relation between femoral neck BMD, trochanteric soft tissue thickness, and both $\varphi_{\text {peak }}$ and $\varphi_{\text {attenuated }}$ and time to hip fracture, death, lost to follow up, or end of follow up (12/31/2005). All models were sex-specific. Models were not adjusted for history of previous hip fracture because the association between factor-of-risk and hip fracture is not likely to be confounded by a history of prior fracture. In addition, these prior hip fractures occurred, on average, 11 years prior to the 
bone density exam and thus are not likely to represent a major problem. To further examine the impact of Factor-of-Risk and its relationship with BMD, we specifically performed an analysis using the components of factor-of-risk: force (both peak and attenuated), femoral strength and estimated trochanteric soft tissue thickness. Models were also examined separately by fracture location (intertrochanteric vs. femoral neck). All analyses were conducted using the SAS statistical analysis package (SAS Institute Inc., Cary, NC, U.S.A.; version 9.1).

All participants have given informed consent for the data collection and this study has undergone institutional review by both the Hebrew SeniorLife and the Boston University Medical Center Institutional Review Boards.

\section{Results}

In the 425 men and 675 women who had valid femoral neck BMD, mean age was 76 years \pm 5.1 (range 67 to 95 years) and mean BMI was $26.8 \mathrm{~kg} / \mathrm{m}^{2} \pm 4.6$. Population characteristics are shown in Table 1, by sex and fracture status. Over a median follow-up time of 11.3 years, 136 hip fractures occurred, with 26 of those occurring in men. There were 8 intertrochanteric and 17 femoral neck hip fractures in men ( 1 unknown location) and 54 intertrochanteric and 52 femoral neck hip fractures in women (4 unknown locations). Analyzing the data separately by fracture location did not result in any statistically significant findings (all $p>0.20$ ). Thus, results of the location-specific analysis are not presented. All variables of interest (except age) differed between men and women, thus all analyses were performed separately by sex. The assumptions of the Cox proportional hazards regressions were met for all models.

Of the 675 women, 13 had invalid, negative estimates for attenuated force. This was due to the fact that in the OFELY cohort, in whom the regression equation between BMI and trochanteric soft tissue thickness was developed, there were no women with a BMI greater than $35 \mathrm{~kg} / \mathrm{m}^{2}$. Since, in our study, these 13 women had BMI greater than $35 \mathrm{~kg} / \mathrm{m}^{2}$, we chose not to extrapolate beyond the limits of the regression equation. These 13 women were given a value of $5 \mathrm{~N}$ for their attenuated force, which was the lowest value observed in our cohort. Models were examined with and without these 13 women and no difference in results was observed, thus the results presented include these 13 women.

Mean femoral neck BMD was $0.777 \pm 0.147 \mathrm{~g} / \mathrm{cm}^{2}$ (range $0.182-1.556 \mathrm{~g} / \mathrm{cm}^{2}$ ). The average estimated femoral strength was 5,808 $\pm 1,207 \mathrm{~N}$ and ranged from 923 to 12,197 N. As expected, in both men and women, decreased femoral neck BMD was associated with an increased risk of hip fracture, adjusting for age ( $\mathrm{HR}=2.2$ men (95\% CI: 1.3, 3.7); $\mathrm{HR}=1.7$ women $(95 \%$ CI: 1.4, 2.1) for 1 SD decrease in femoral neck BMD). Decreased trochanteric soft tissue thickness was associated with increased hip fracture risk in women $(\mathrm{HR}=1.5$ per $\mathrm{SD}, 95 \% \mathrm{CI}: 1.2,1.9$ ), but there was no association in men.

Higher $\varphi_{\text {peak }}$ and $\varphi_{\text {attenuated }}$ were associated with increased risk of hip fracture, adjusting for age (Table 2). A one standard deviation increase in $\varphi_{\text {peak }}$ was associated with a hazard ratio (HR) of 1.88 in men (95\% CI: 1.38, 2.55) and 1.23 in women (95\% CI: 1.10, 1.37).

Similarly, for $\varphi_{\text {attenuated }}$, the HR for hip fracture was 1.78 in men (95\% CI: 1.30, 2.44) and 1.41 in women (95\% CI: $1.26,1.58$ ). Table 3 shows the age-adjusted hazard ratios and $95 \%$ confidence intervals for the association between the components of the factor-of-risk and hip fracture risk, adjusting for age. In both men and women, we saw that femoral strength, the denominator of factor-of-risk, was strongly associated with risk of hip fracture, with an increased hazard of 2.0-2.5 in men and 1.60 in women per standard deviation decrease in femoral strength. In men, increased fall force, both peak and attenuated, along with 
decreased estimated trochanteric soft tissue thickness were associated with an increased risk of hip fracture, although not statistically significant. In women, a model containing both attenuated fall force and femoral strength showed a significant $30 \%$ increased risk of hip fracture for each standard deviation increase in attenuated fall force along with a $60 \%$ increase of hip fracture per standard deviation decline in femoral strength suggesting that the contribution of fall force to hip fracture risk is distinct from that of the contribution of femoral strength. In a model containing peak fall force, trochanteric soft tissue thickness and femoral strength, fall force was no longer significantly associated with hip fracture, but decreased femoral strength and trochanteric soft tissue thickness contributed independently to the prediction of hip fracture. Although subjects with a prior history of hip fracture were not excluded from this analysis, nor did we adjust for prior hip fracture, a sensitivity analysis revealed that excluding those subjects with a prior hip fracture did not change the results.

\section{Discussion}

We found that increased factor-of-risk values, both $\varphi_{\text {peak }}$ and $\varphi_{\text {attenuated }}$, were associated with increased hip fracture risk in men ( 80\% increased risk per 1SD increase in $\varphi)$ and in women (23\%-41\% increased risk per 1 SD increase in $\varphi$ ), even after adjusting for age. In women, separating out the components of the factor-of-risk revealed that attenuated force and estimated trochanteric soft tissue thickness were associated with hip fracture risk, in addition to the femoral strength term. Since femoral strength is calculated from a linear regression using BMD, these results indicate that in women, the components of factor-ofrisk, specifically attenuated fall force and estimated soft tissue thickness, are significant predictors of hip fracture even after accounting for the influence of femoral neck BMD. The same trend of increased risk was seen in the men, although the results were not statistically significant. These findings indicate that characteristics related to the fall and/or body habitus (and presumably cushioning of the fall) are associated with hip fracture after accounting for femoral BMD. Analyses examining the association between BMD and risk of hip fracture showed that the association between risk of future hip fracture and low femoral BMD was higher than that of factor of risk.

Two previous studies, one in men and one in women, have examined the association between the factor-of-risk and hip fracture using methods similar to the current study. Nielson et al ${ }^{17}$ examined the association between the factor-of-risk and hip fracture risk in 292 older men (including 70 fracture cases) from the MrOS cohort. They found a small, but significant, increased risk of hip fracture with a $1 \mathrm{SD}$ increase in Factor-of-Risk using peak force and attenuated force $(1.10, \mathrm{p}<.0001$ and $1.09, \mathrm{p}=0.0002$, respectively). The Nielson study did not see any association between hip fracture risk and soft tissue thickness, which is consistent with our results in men. . In men, our study obtained higher odds ratios between factor-of-risk and hip fracture than Nielson et al. This may be due to the fact that we estimated soft tissue thickness using BMI whereas the previous study used a direct measurement of soft tissue thickness.

In a study performed in the OFELY cohort, which examined 63 postmenopausal women (21 hip fractures and 42 controls), Bouxsein et al $^{3}$ found an increased risk of hip fracture with a $1 \mathrm{SD}$ increase in factor-of-risk using peak force and attenuated force $(\mathrm{OR}=1.80, \mathrm{p}=0.09$ and $1.85, \mathrm{p}=0.07$, respectively) and also found that decreased trochanteric soft tissue thickness was associated with increased risk hip fracture $(\mathrm{OR}=1.82, \mathrm{p}=0.02)$. Among the women in our study, the hazard ratios were similar to those seen in the OFELY study.

Our study has several limitations that should be noted. First, we estimated soft tissue thickness using a regression with body mass index. Previous studies have shown ${ }^{24-25,28}$ that low BMI is associated with decreased trochanteric soft tissue thickness overlying the hip so 
it is reasonable to use BMI to estimate this measure. However, the correlation between BMI and trochanteric soft tissue thickness is modest, so it is probable that there is error associated with the estimation. Future studies using directly measured trochanteric soft tissue thickness are needed to confirm our results. Second, we had relatively few hip fractures in men $(n=26)$, which reduced our power to detect an increased risk, and to establish whether the components of the factor of risk were related to hip fracture. Third, the regression equations used for prediction of trochanteric soft tissue thickness came from only a single study, the OFELY cohort. In the OFELY cohort the regression between body mass index and trochanteric soft tissue thickness was derived from a sample in which there were no women with more than $8 \mathrm{~cm}$ of trochanteric soft tissue, and no women with BMI greater than 35 . Our sample included several women with BMI $>40$. This limitation caused these women with BMI > 40 to have an estimated force applied to their femur which was negative. To account for this impossible estimation of force, these women were assigned the lowest positive value for estimated force in our data. A sensitivity analysis revealed that there was no difference in the results if these women were excluded. Fourth, since our population was predominately Caucasian adults, our results may not be applicable to other races and ethnicities.

Additionally, we used femoral neck BMD to estimate femoral strength. Whereas in vitro studies using cadaveric femora report strong associations between femoral BMD and failure load in a sideways fall configuration ${ }^{27}$, and at least one previous study ${ }^{29}$ has reported a strong correlation $(\mathrm{r}=0.79)$ between experimentally measured femoral strength and femoral neck BMD as measured by DPA (Lunar DP3). There have also been multiple studies reporting strong correlations between femoral strength and BMD as measured by DXA ${ }^{30-32}$. Despite these studies, we acknowledge that more sophisticated approaches, such as QCTbased finite element analysis ${ }^{18,33}$, may provide more accurate femoral strength estimates. Indeed, Orwoll et al ${ }^{18}$, who used QCT-based finite element analysis to estimates femoral strength in older men, reported a 4-fold increased risk of hip fracture per standard deviation increase in the load-to-strength ratio, a measure similar to the factor-of-risk, except that they did not incorporate the cushioning effects of trochanteric soft tissue thickness into their estimates of femoral loading. For this study, we did not have data available to better estimate femoral strength such as finite element analysis. Finally, in this analysis, we used baseline measurements of BMI and BMD, even though there was significant time between the baseline measurements and the end of follow-up in this study and it is possible that BMI or BMD could have changed over the follow-up period. However when we restricted our analysis to a ten year follow-up period, we observed the same results.

Despite the aforementioned limitations, our study also has several strengths. To our knowledge, this is the first study to examine the association between factor-of-risk and hip fracture risk in a large, population-based cohort of both men and women using incident fractures. Our study sample includes both men and women, which enables us to generalize the results to both genders.

In conclusion, a biomechanical approach to fracture risk assessment, the factor-of-risk, is associated with hip fracture risk in men and in women. Furthermore, in women, the components of factor-of-risk, namely attenuated force and estimated trochanteric soft tissue thickness, predict hip fracture even when BMD is in the model. This provides the rationale to conduct additional studies of factor-of-risk using a direct measurement of trochanteric soft tissue thickness to predict hip fracture in larger samples of men and women. These results motivate development of new protocols for DXA scans that integrate measures of soft tissue thickness into the software to improve prediction of hip fracture risk. Most importantly, since the components of factor-of-risk predicted fracture, the routine 
measurement of the factor-of-risk might be used to enhance the currently available instruments used to predict fracture risk.

\section{Acknowledgments}

We acknowledge grant funding for this project was provided by: American College of Rheumatology Research and Education Foundation's Abbott Health Professional Graduate Student Research Preceptorship; the National Institute of Arthritis and Musculoskeletal and Skin Diseases and the National Institute on Aging (R01-AR/AG 41398 and AR053986); and by the National Heart, Lung and Blood Institute's Framingham Heart Study (N01HC-25195).

Funding for this project was provided by: American College of Rheumatology Research and Education Foundation's Abbott Health Professional Graduate Student Research Preceptorship; the National Institute of Arthritis and Musculoskeletal and Skin Diseases and the National Institute on Aging (R01-AR/AG 41398, AR053986); and by the National Heart, Lung and Blood Institute's Framingham Heart Study (N01-HC-25195).

\section{References}

1. Burge R, Dawson-Hughes B, Solomon DH, Wong JB, King A, Tosteson A. Incidence and economic burden of osteoporosis-related fractures in the United States, 2005-2025. J Bone Miner Res. 2007; 22:465-75. [PubMed: 17144789]

2. US Department of Health and Human Services. Bone Health and Osteoporosis: A Report of the Surgeon General. U.S. Department of Health and Human Services, Office of the Surgeon General; Rockville, MD: 2004.

3. Bouxsein ML, Szulc P, Munoz F, Thrall E, Sornay-Rendu E, Delmas PD. Contribution of trochanteric soft tissues to fall force estimates, the factor of risk, and prediction of hip fracture risk. J Bone Miner Res. 2007; 22:825-31. [PubMed: 17352651]

4. Kanis JA, Johnell O, Oden A, Johansson H, McCloskey E. FRAX and the assessment of fracture probability in men and women from the UK. Osteoporos Int. 2008; 19:385-97. [PubMed: 18292978]

5. Wainwright SA, Marshall LM, Ensrud KE, et al. Hip fracture in women without osteoporosis. J Clin Endocrinol Metab. 2005; 90:2787-93. [PubMed: 15728213]

6. Kaptoge S, Benevolenskaya LI, Bhalla AK, et al. Low BMD is less predictive than reported falls for future limb fractures in women across Europe: results from the European Prospective Osteoporosis Study. Bone. 2005; 36:387-98. [PubMed: 15777673]

7. Jarvinen TL, Sievanen H, Khan KM, Heinonen A, Kannus P. Shifting the focus in fracture prevention from osteoporosis to falls. BMJ. 2008; 336:124-6. [PubMed: 18202065]

8. Keaveny TM, Bouxsein ML. Theoretical implications of the biomechanical fracture threshold. J Bone Miner Res. 2008; 23:1541-7. [PubMed: 18410232]

9. Hayes, WC. Implications for assessment of fracture risk. In: Mow, VC.; Hayes, WC., editors. Basic Orthopaedic Biomechanics. Raven Press; New York: 1991. p. 93-142.

10. Bouxsein, M. Osteoporosis IIIe. Academic Press, Inc.; San Diego: 2007. Biomechanics of AgeRelated Fractures; p. 601-16.

11. Bouxsein ML, Melton Iii LJ 3rd, Riggs BL, et al. Age- and sex-specific differences in the factor of risk for vertebral fracture: a population-based study using QCT. J Bone Miner Res. 2006; 21:1475-82. [PubMed: 16939406]

12. Riggs BL, Melton LJ, Robb RA, et al. Population-based analysis of the relation of whole bone strength indices and fall-related loads to age- and sex-specific patterns of hip and wrist fractures. $\mathrm{J}$ Bone Miner Res. 2006; 21:315-23. [PubMed: 16418788]

13. Melton LJ 3rd, Riggs BL, Keaveny TM, et al. Structural determinants of vertebral fracture risk. J Bone Miner Res. 2007; 22:1885-92. [PubMed: 17680721]

14. Hayes WC, Myers ER, Morris JN, Gerhart TN, Yett HS, Lipsitz LA. Impact near the hip dominates fracture risk in elderly nursing home residents who fall. Calcif Tissue Int. 1993; 52:192-8. [PubMed: 8481831]

15. Greenspan SL, Myers ER, Maitland LA, Resnick NM, Hayes WC. Fall severity and bone mineral density predict hip fracture in the elderly. JAMA. 1994; 271:128-33. [PubMed: 8264067] 
16. Greenspan SL, Myers ER, Kiel DP, Parker RA, Hayes WC, Resnick NM. Fall direction, bone mineral density, and function: risk factors for hip fracture in frail nursing home elderly. Am $\mathrm{J}$ Med. 1998; 104:539-45. [PubMed: 9674716]

17. Nielson CM, Bouxsein ML, Freitas SS, Ensrud KE, Orwoll ES. Trochanteric soft tissue thickness and hip fracture in older men. J Clin Endocrinol Metab. 2009; 94:491-6. [PubMed: 19017753]

18. Orwoll ES, Marshall LM, Nielson CM, et al. Finite element analysis of the proximal femur and hip fracture risk in older men. J Bone Miner Res. 2009; 24:475-83. [PubMed: 19049327]

19. Dawber TR, Meadors GF, Moore FE. Epidemiological approaches to heart disease: the Framingham Study. Am J Pub Health. 1951; 41:279-86.

20. Hannan MT, Felson DT, Anderson JJ. Bone mineral density in elderly men and women: results from the Framingham osteoporosis study. J Bone Miner Res. 1992; 7:547-53. [PubMed: 1615761]

21. Kannel WB, Kannel C, Paffenbarger RS Jr. Cupples LA. Heart rate and cardiovascular mortality: the Framingham Study. Am Heart J. 1987; 113:1489-94. [PubMed: 3591616]

22. Sytkowski PA, D'Agostino RB, Belanger A, Kannel WB. Sex and time trends in cardiovascular disease incidence and mortality: the Framingham Heart Study, 1950-1989. Am J Epidemiol. 1996; 143:338-50. [PubMed: 8633618]

23. Kiel DP, Felson DT, Anderson JJ, Wilson PW, Moskowitz MA. Hip fracture and the use of estrogens in postmenopausal women. The Framingham Study. N Engl J Med. 1987; 317:1169-74. [PubMed: 3657888]

24. van den Kroonenberg AJ, Hayes WC, McMahon TA. Hip impact velocities and body configurations for voluntary falls from standing height. J Biomech. 1996; 29:807-11. [PubMed: 9147979]

25. Robinovitch SN, Hayes WC, McMahon TA. Prediction of femoral impact forces in falls on the hip. J Biomech Eng. 1991; 113:366-74. [PubMed: 1762432]

26. Robinovitch SN, McMahon TA, Hayes WC. Force attenuation in trochanteric soft tissues during impact from a fall. J Orthop Res. 1995; 13:956-62. [PubMed: 8544034]

27. Roberts BJ, Thrall E, Muller JA, Bouxsein ML. Comparison of hip fracture risk prediction by femoral aBMD to experimentally measured factor of risk. Bone. 2010; 46:742-6. [PubMed: 19854307]

28. Maitland LA, Myers ER, Hipp JA, Hayes WC, Greenspan SL. Read my hips: measuring trochanteric soft tissue thickness. Calcif Tissue Int. 1993; 52:85-9. [PubMed: 8443696]

29. Beck TJ, Ruff CB, Warden KE, Scott WW Jr. Rao GU. Predicting femoral neck strength from bone mineral data. A structural approach. Invest Radiol. 1990; 25:6-18. [PubMed: 2298552]

30. Cheng XG, Lowet G, Boonen S, et al. Assessment of the strength of proximal femur in vitro: relationship to femoral bone mineral density and femoral geometry. Bone. 1997; 20:213-8. [PubMed: 9071471]

31. Cheng XG, Lowet G, Boonen S, Nicholson PH, Van der Perre G, Dequeker J. Prediction of vertebral and femoral strength in vitro by bone mineral density measured at different skeletal sites. J Bone Miner Res. 1998; 13:1439-43. [PubMed: 9738516]

32. Bouxsein ML, Coan BS, Lee SC. Prediction of the strength of the elderly proximal femur by bone mineral density and quantitative ultrasound measurements of the heel and tibia. Bone. 1999; 25:49-54. [PubMed: 10423021]

33. Keaveny TM. Biomechanical computed tomography-noninvasive bone strength analysis using clinical computed tomography scans. Ann N Y Acad Sci. 2010; 1192:57-65. [PubMed: 20392218] 


\section{Table I}

Descriptive characteristics of the men and women of the Framingham Study with baseline hip BMD scans between 1988-1989. (mean \pm SD, unless otherwise noted)

\begin{tabular}{|l|c|c|c|c|}
\hline & \multicolumn{2}{|c|}{ Men } & \multicolumn{2}{c|}{$\begin{array}{c}\text { Women } \\
\text { n=675 }\end{array}$} \\
\hline & $\begin{array}{c}\text { Fracture } \\
\mathbf{n = 2 6}\end{array}$ & $\begin{array}{c}\text { Non-Fracture } \\
\mathbf{n = 3 9 9}\end{array}$ & $\begin{array}{c}\text { Fracture } \\
\mathbf{n = 1 1 0}\end{array}$ & $\begin{array}{c}\text { Non-Fracture } \\
\mathbf{n = 5 6 5}\end{array}$ \\
\hline Age (years) & $78.4(6.29)$ & $75.0(4.90)^{a}$ & $77.1(5.86)$ & $75.4(4.89)^{a}$ \\
\hline Weight (lbs) & $173.4(25.18)$ & $173.9(28.21)$ & $135.3(26.84)$ & $144.3(26.20)^{b}$ \\
\hline Height (inches) & $67.4(3.34)$ & $67.1(2.69)$ & $61.5(2.74)$ & $61.5(2.44)$ \\
\hline BMI (kg/m²) & $26.9(4.22)$ & $27.2(3.98)$ & $25.2(4.82)$ & $26.8(4.85)^{b}$ \\
\hline History of hip fracture & $2(7.14 \%)$ & $0(0.00 \%)$ & $25(19.69 \%)$ & $0(0.00 \%)$ \\
\hline Femoral neck BMD (g/cm $\left.{ }^{2}\right)$ & $0.778(0.119)$ & $0.878(0.143)^{b}$ & $0.665(0.104)$ & $0.730(0.114)^{c}$ \\
\hline $\begin{array}{l}\text { Estimated Trochanteric Soft } \\
\text { Tissue Thickness (mm) }\end{array}$ & $29.55(9.89)$ & $30.14(9.32)$ & $49.50(16.78)$ & $55.33(16.83)^{b}$ \\
\hline Estimated femoral strength (N) & $5817(976)$ & $6639(1171)^{b}$ & $4888(852)$ & $5419(933)^{c}$ \\
\hline Peak fall force (N) & $7789(642)$ & $7777(708)$ & $5816(610)$ & $6008(575)^{b}$ \\
\hline Attenuated fall force (N) & $5692(647)$ & $5637(498)$ & $2317(751)$ & $2092(783)^{a}$ \\
\hline Factor-of-Risk, peak & $1.37(0.22)$ & $1.20(0.20)^{c}$ & $1.21(0.18)$ & $1.14(0.28)^{b}$ \\
\hline Factor-of-Risk, attenuated & $1.00(0.17)$ & $0.87(0.16)^{c}$ & $0.49(0.17)$ & $0.41(0.21)^{c}$ \\
\hline
\end{tabular}

$a_{\mathrm{p}<0.01}$

$b_{\mathrm{p}<0.001 ;}$

${ }_{\mathrm{p}}^{c}<0.0001$ 


\section{Table II}

Adjusted hip fracture hazard ratios $(95 \% \mathrm{CI})$ in men and women for a 1 standard deviation $(\mathrm{SD})$ change.

\begin{tabular}{|c|c|c|}
\hline Model & Men & Women \\
\hline \multicolumn{3}{|l|}{ Age-adjusted } \\
\hline Estimated Soft Tissue Thickness \# & $1.08(0.71,1.62)$ & $1.51(1.20,1.91)$ \\
\hline Factor-of-Risk $_{\text {peak }}{ }^{\dagger}$ & $1.88(1.38,2.55)$ & $1.23(1.10,1.37)$ \\
\hline Factor-of-Risk $_{\text {attenuated }}{ }^{\dagger}$ & $1.78(1.30,2.44)$ & $1.41(1.26,1.58)$ \\
\hline Femoral neck BMD $\#$ & $2.20(1.32,3.66)$ & $1.67(1.35,2.06)$ \\
\hline
\end{tabular}

${ }_{\text {decrease }}$

$\dagger_{\text {increase }}$ 
Table III

Age-adjusted hip fracture hazard ratios $(95 \% \mathrm{CI})$ for components of factor-of-risk in men and women for a 1 standard deviation (SD) change.

\begin{tabular}{|l|l|l|c|}
\hline Model & Force term ${ }^{\dagger}$ & $\begin{array}{c}\text { Estimated } \\
\text { Femoral } \\
\text { Strength }^{\#}\end{array}$ & $\begin{array}{c}\text { Estimated Soft } \\
\text { Tissue } \\
\text { Thickness }\end{array}$ \\
\hline Men & & & \\
\hline $\begin{array}{c}\text { Attenuated force + femoral } \\
\text { strength }\end{array}$ & $1.34(0.86,2.08)$ & $2.27(1.35,3.82)$ & - \\
\hline $\begin{array}{l}\text { Peak force + femoral strength }+ \\
\text { estimated soft tissue thickness }\end{array}$ & $1.64(0.90,3.00)$ & $2.46(1.44,4.22)$ & $1.14(0.61,2.14)$ \\
\hline Women & & & \\
\hline $\begin{array}{c}\text { Attenuated force + femoral } \\
\text { strength }\end{array}$ & $1.34(1.07,1.68)$ & $1.64(1.31,2.04)$ & - \\
\hline $\begin{array}{l}\text { Peak force + femoral strength }+ \\
\text { estimated soft tissue thickness }\end{array}$ & $1.17(0.83,1.65)$ & $1.62(1.27,2.06)$ & $1.47(1.02,2.12)$ \\
\hline
\end{tabular}

\# decrease

${ }^{\dagger}$ increase 